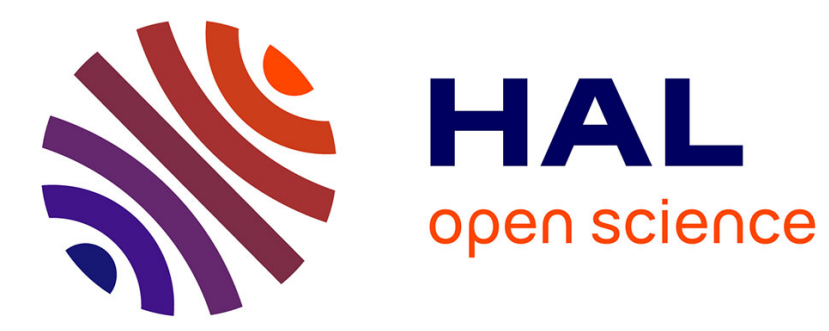

\title{
Fatigue analysis-based numerical design of stamping tools made of cast iron
}

Khalil Ben Slima, Luc Penazzi, Catherine Mabru, François Ronde Oustau

\section{To cite this version:}

Khalil Ben Slima, Luc Penazzi, Catherine Mabru, François Ronde Oustau. Fatigue analysis-based numerical design of stamping tools made of cast iron. International Journal of Advanced Manufacturing Technology, 2013, 10.1007/s00170-012-4597-y . hal-00801355

\section{HAL Id: hal-00801355 https://hal.science/hal-00801355}

Submitted on 15 Mar 2013

HAL is a multi-disciplinary open access archive for the deposit and dissemination of scientific research documents, whether they are published or not. The documents may come from teaching and research institutions in France or abroad, or from public or private research centers.
L'archive ouverte pluridisciplinaire HAL, est destinée au dépôt et à la diffusion de documents scientifiques de niveau recherche, publiés ou non, émanant des établissements d'enseignement et de recherche français ou étrangers, des laboratoires publics ou privés. 


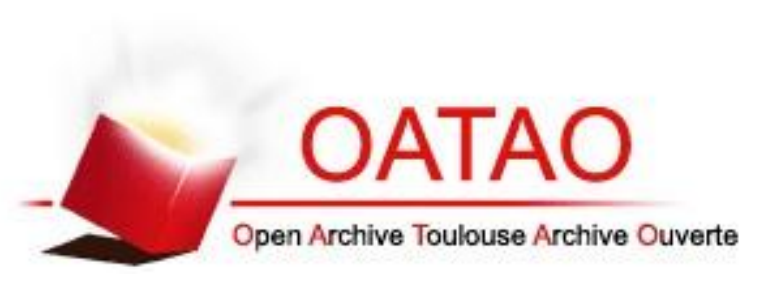

\section{Open Archive Toulouse Archive Ouverte (OATAO)}

OATAO is an open access repository that collects the work of Toulouse researchers and makes it freely available over the web where possible.

This is an author-deposited version published in: http://oatao.univ-toulouse.fr/ Eprints ID: 8495

To link to this article: DOI: 10.1007/s00170-012-4597-y URL: http://dx.doi.org/10.1007/s00170-012-4597-y

To cite this version: Ben Slima, Khalil and Penazzi, Luc and Mabru, Catherine and Ronde-Oustau, François Fatigue analysis-based numerical design of stamping tools made of cast iron. (2012) The International Journal of Advanced Manufacturing Technology. ISSN 0268-3768 


\title{
Fatigue analysis-based numerical design of stamping tools made of cast iron
}

\author{
K. Ben Slima • L. Penazzi • C. Mabru • F. Ronde-Oustau
}

\begin{abstract}
This work concerns stress and fatigue analysis of stamping tools made of cast iron with an essentially pearlitic matrix and containing foundry defects. Our approach consists at first, in coupling the stamping numerical processing simulations and structure analysis in order to improve the tool stiffness geometry for minimizing the stress state and optimizing their fatigue lifetime. The method consists in simulating the stamping process by considering the tool as a perfect rigid body. The estimated contact pressure is then used as boundary condition for FEM structure loading analysis of the tool. The result of this analysis is compared with the critical stress limit depending on the automotive model. The acceptance of this test allows calculating the fatigue lifetime of the critical zone by using the $S-N$ curve of corresponding load ratio. If the prescribed tool life requirements are not satisfied, then the critical region of the tool is redesigned and the whole simulation procedures are reactivated. This method is applied for a cast iron EN-GJS-600-3. The stress-failure $(S-N)$ curves for this material is determined at room temperature under push pull loading with different load ratios $R=\sigma_{\min } / \sigma_{\max }=-2, R=-1$ and $R=0.1$. The effects of the foundry defects are determined by SEM observations of crack initiation sites. Their presence in tested specimens is associated with a reduction of fatigue lifetime by a factor of 2 . However, the effect of the load ratio is more important.
\end{abstract}

Keyword Fatigue $\cdot$ Defects $\cdot$ Stamping $\cdot$ Tools $\cdot$ Cast iron

\author{
K. B. Slima $\cdot$ L. Penazzi $\cdot$ F. Ronde-Oustau \\ Université de Toulouse, ICA, Mines Albi, \\ Campus Jarlard, \\ 81013 Albi Cedex 9, France \\ C. Mabru $(\bowtie)$ \\ Université de Toulouse, ICA, ISAE, \\ BP 54032, 31055 Toulouse Cedex 4, France \\ e-mail: catherine.mabru@isae.fr
}

\section{Introduction}

Nodular cast irons are used in automotive car industry for stamping tools because of their high mechanical characteristics and easy manufacturing due to their high cast ability. These alloys present high fracture toughness, high fatigue limit (endurance), and a low production cost. Their characteristics allow using them as structural material for stamping tools [1, 2], mechanical parts [3-7], and pump part [8]. However, the complex geometry of the stamping tool entails the presence of foundry defect in their structure. These defects are the main fatigue life-limiting factors causing premature fracture of material $[1,6]$. Some authors were interested in studying the fatigue behavior of this material $[5,7,8]$ others in determining the effect of foundry defects on the fatigue behavior applied to other nuances of this material family $[1,6,9,10]$.

\subsection{Stress analysis of stamping tools}

In most general software of sheet metal forming, tools are considered as perfect rigid body. Several authors have aimed to reduce the spring-back [11, 12] of sheet by the estimation of the plastic deformation of working surfaces and subsurfaces of stamping tools. Other authors proposed to optimize the mass and the rigidity of the tool by topology optimization $[13,14]$.

Firat et al. [11] have reported a maximal local stress of about $510 \mathrm{MPa}$ and a maximal displacement of $0.86 \mathrm{~mm}$ for critical zones of a stamping tool under about $680 \mathrm{kN}$ loading. This elastic stress was greater than the yield stress (400 MPa). To reduce the maximal local stress, authors optimized the stamping tool geometry for obtaining $350 \mathrm{MPa}$ and $0.6 \mathrm{~mm}$ for maximal stress and displacement, respectively. 
In the case of topological optimization in order to improve the structure stiffness and to reduce the weight of the stamping tool, Nilsson et al. [13] chose to increase the level of Von Mises stresses from 110 to $140 \mathrm{MPa}$, to reduce the maximum displacement and the weight of the tool of about 15 and $20 \%$, respectively.

It therefore seemed that the estimate of the maximal stress and displacement of a stamping tool is a major element in the step design of tools. However, the fatigue of stamping tools is of major concern for optimal life designing and cycling assessments.

For the tools designed for a large production where the number of produced sheets is superior to $10^{7}$ cycles, the fatigue limit of material is generally employed as a data to be compared to the stress occurring in the tool. In the case of tools for limited production and with limited fatigue lives (where the number of cycles ranges from $10^{5}$ to $10^{7}$ cycles), the previous approach is very conservative and restricts the possible optimization concerning weight and rigidity. Taking into account the fatigue stress for a given lifetime (corresponding to the given number of sheets that the tool is supposed to produce) in the design process would then lead to improve the optimization. This will be done in the methodology proposed in the present paper.

\subsection{Tools material}

Only few works found in the literature concern the materials of working surfaces and structure of the stamping tools of bodywork components. The technical guides of French car manufacturers CNOMO (http://www.cnomo.com, December 2010, EM24.15.050) recommend the choice of tools materials linked to the application type, the sheet dimension and machining parameters, or the cost of tool. The choice of the material grade can also be linked to specifications of the surface hardness and therefore to the capacity of the microstructure to attain these characteristics by heat treatment (T7).

For automotive tools of bodywork subjected to fatigue solicitation in transition regime near the fatigue limit $\left(10^{5}-10^{7}\right.$ cycles), the rule CNOMO recommends the use of cast iron ENGJS-600-3. Griswold [3], Hubner [4], and Abebe [8] reported the use of this alloy for the manufacturing of components in the automotive industry. The authors presented the mechanical properties of this alloy for monotonic and fatigue experiments with a load ratio $R=-1$. In another study, Shirani [15] showed that the load ratio and the specimen diameter have an influence on the fatigue behavior of a cast iron EN-GJS-400.

In order to include fatigue stress data in the optimization process, it is then necessary to increase knowledge on the fatigue behavior of EN-GJS-600-3 alloy and in particular to study the influence of the load ratio. In the present work, the analysis of the first results of tool structure analysis shows that the load ratio is not constant in the stamping tool. So for recovering a large range of the material behavior, fatigue tests will be conducted with three different load ratios and the $S-N$ curve will be established for each studied load ratio.

\subsection{Design methodology}

During the last decade, a considerable progress has been accomplished in results post-treatment of stamping numerical simulation allowing to achieve the local loading instead of the global ones [14]. These local loads (the local contact pressure at sheet/tool interface $[1,16]$ ) can be used as boundary conditions for numerical simulation of mechanical solicitations of tool considering the nodal efforts [11]. Del Pozo [17] proposed a methodology to determine the maximal displacement of the different part of the stamping tool while considering the group die-press (composed by the different parts of the stamping tool as die, punch, and blank holder, assembled with a simplified press model) as a deformable body. So, this methodology is very costly in CPU time calculation for the used stamping tools because of their large dimensions. In the present paper, the proposed methodology for stamping tools design allows predicting independently the stress state in any part of tools. It consists in coupling the stamping numerical processing simulation and structure analysis by using the maximum contact pressure in the interface tool/sheet as boundary conditions for FEM structure loading analysis of the tool. So this procedure will permit to reduce the CPU time calculation and to improve the precision of tool structure analysis.

\section{Design procedure}

In automotive industry, the simulation of stamping process is realized by Autoform $(\mathrm{C}$ or PAMSTAMP $\subset$. This study is realized in collaboration with the automotive industrial PSA Peugeot Citroen. The simulation of stamping process is realized, generally by Autoform (C) and occasionally by PAMSTAMPC in the more complicated cases. Only the tool can be considered as rigid body in this software. However, the simulation of the stamping process with a deformable tool in Abaqus (C) (software used by the industrial partner for stress analysis) or any FEM codes requires an enormous calculation time and this software does not allow giving a precision as Autoform $(\mathrm{C}$ or PAMSTAMPC. To reduce the calculation time of the process and tool design, a new methodology of stamping tool calculation is proposed. Its flowchart is presented in Fig. 1. At first step, the procedure consists in designing the tool geometry from the part geometry to be produced, and in simulating the stamping process by considering the tool as a perfect rigid body. The initial 


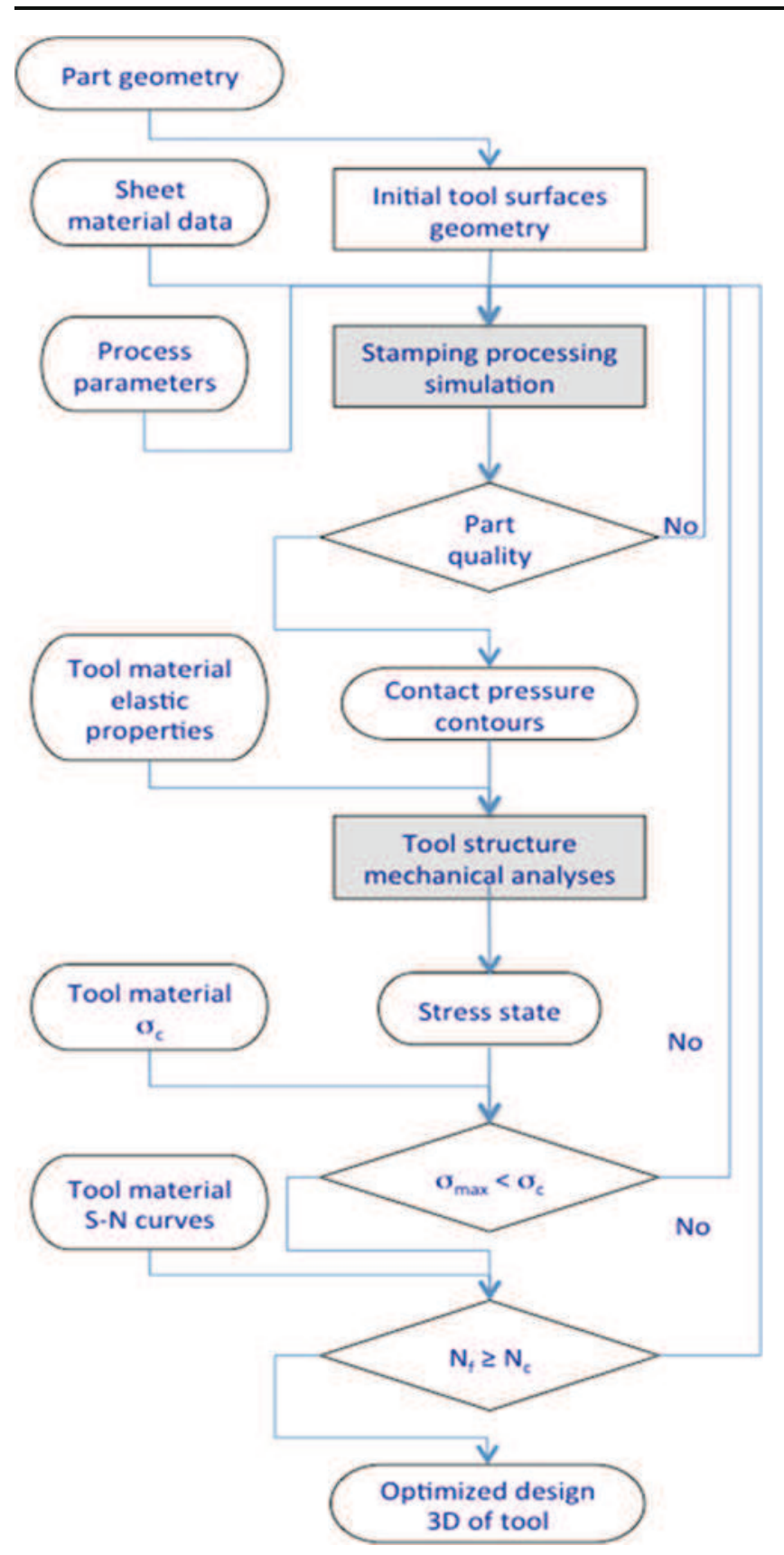

Fig. 1 Flowchart of the proposed procedure

tool surface can be modified if the prescribed stamping quality requirements are not satisfied and the whole simulation procedures are then reactivated. The second step consists in using the maximum contact pressure, obtained by numerical simulation of stamping process, as boundary condition for structure loading FEM analysis (Figs. 2 and 3). The material is considered as an isotropic elastic material with an elastic modulus of $170 \mathrm{GPa}$ and Poisson's ratio of 0.25 . Then, the general state of stress is analyzed and the maximal stress is compared with the critical maximal stress $\sigma_{\mathrm{c}}$ of the tool material. In this case, the cast iron EN-GJS$600-3$ is used. The critical stress is considered as

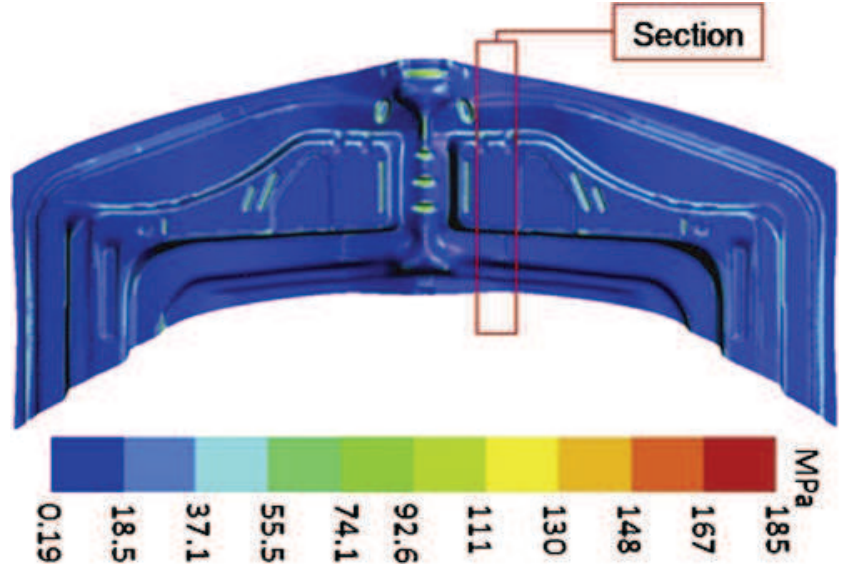

Fig. 2 Maximum contact pressures in the sheet: results of stamping simulation used as reference of tool structure analysis (Courtesy of PSA Peugeot-Citroen)

conventional yield stress obtained by monotonic tests; it is equal to $408 \mathrm{MPa}$ in traction and $-449 \mathrm{MPa}$ (Table 1) in the compression case. If the maximal stress is lower than $\sigma_{\mathfrak{c}}$, the calculation of the lifetime of the tool critical zones is performed via experimental $S-N$ fatigue curves with various load ratios. The choice of the critical number of cycle $N_{\mathrm{c}}$ is linked to the type of automotive car. The acceptance of this second criterion allows validating the tool geometry. Otherwise, if one of both criteria fails, the critical region of the tool is redesigned and the whole simulation procedures are reactivated.

\section{Initial tool structure analysis}

As part of the design process, the stamping tool must be analyzed for the various loads that it will experience during its service life. A prime purpose is to assess whether the tool will be able to resist these loads.

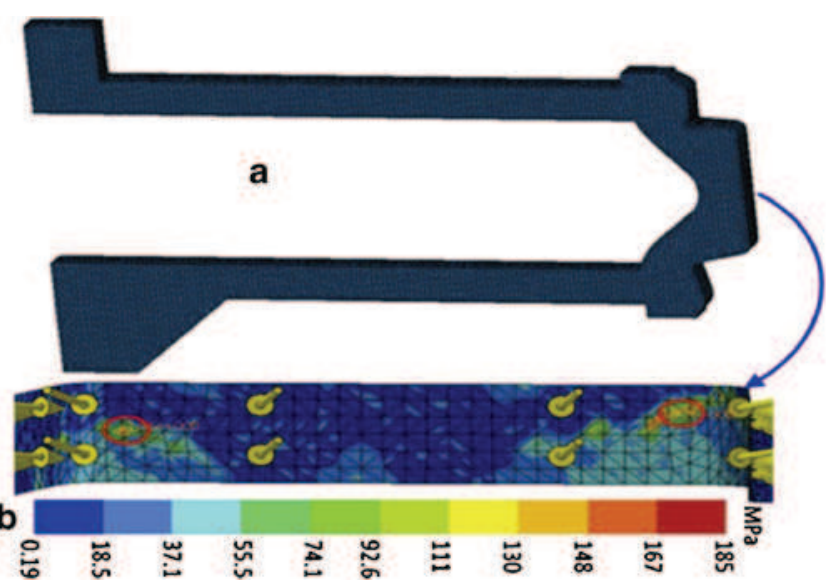

Fig. 3 Part used in this study:(a) Finite elements mesh of the section of stamping tool, $(b)$ maximum contact pressure applied on upper face 
Table 1 Mechanical properties of the nodular cast iron EN-GJS-600-3

\begin{tabular}{lcccc}
\hline $\mathrm{E}(\mathrm{GPa})$ & $\mathrm{Rp}_{0.2 \text { trac }}(\mathrm{MPa})$ & $\mathrm{Rp}_{0.2 \text { comp }}(\mathrm{MPa})$ & $\sigma_{\mathrm{U}}(\mathrm{MPa})$ & $A(\%)$ \\
\hline 169 & 408 & 449 & 640 & 3.6 \\
\hline
\end{tabular}

\subsection{Load cases}

The main load case to be considered is the pressing phase with the maximum level of punching effort. The contact pressure on sheet/tool interface is obtained by stamping process numerical simulation as can be observed in Fig. 2 (Autoform (C). A maximum value of $170 \mathrm{MPa}$ is observed in some radii but average value of $20 \mathrm{MPa}$ is observed on planar faces. These data are used as initial boundary conditions for the tool structure analysis. Other load cases, such as clamping of blank holder or the tool handling, also may be taken into account.

\subsection{Studied case}

In order to minimize the CPU time calculations, only a short section (Fig. 3), of the stamping tool is considered. Due to the wall thickness of the tool, about $40 \mathrm{~mm}$ minimum, a short section of $35 \mathrm{~mm}$ wide has been chosen. A mesh with about 38,000 nodes and 20,000 elements is obtained. Two load cases are studied: (1) stamping case at maximum punch force and (2) gravity case. An isotropic elastic behavior is considered. The bottom face of the section is fixed. Four-node tetrahedral elements, type C3D4, are used to mesh the part. The size of the elements is around $5 \mathrm{~mm}$. The structure analysis is performed with the software Abaqus $($ Standard V6.9.

\subsubsection{Stamping load}

The pressure load defined by the contact pressure obtained by the stamping processing simulation (Fig. 2) is applied on the elements of the active face. A Perl programming language has been developed to read "Maximum contact pressure" on tool-sheet interface, stored at sheet nodes, and write the pressure on the elements at the upper face of tool model. Perl is an interpreted programming language adapted to manipulation of files and for data treatment. Perl takes up features from programming languages $\mathrm{C}$, shell scripting. The mean value is around $20 \mathrm{MPa}$ and the maximum pressure is about $170 \mathrm{MPa}$ (Fig. 3). The lower face of the part model is embedded. The results of stress analysis are illustrated in Figs. 4 and 5 , showing respectively the Von-Mises equivalent stress distribution $\sigma_{\text {eq }}$ and the principal maximal stress $\sigma_{33}$.

A maximum equivalent stress of $210 \mathrm{MPa}$ is observed in the upper radius on internal face of tool (Fig. 4). The

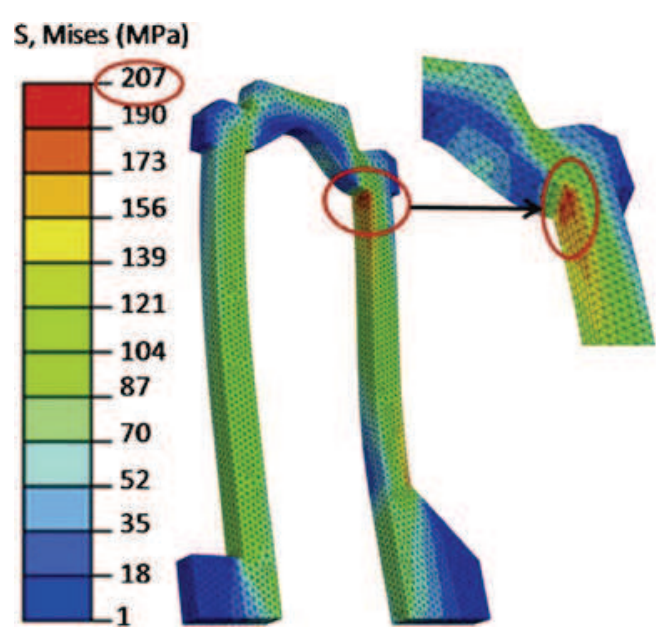

Fig. 4 Result of calculation: Von-Mises stress distribution

analysis of all components shows an almost uniaxial state of stress. The map of the $\sigma_{33}$ stress component shows a lower value close to $-220 \mathrm{MPa}$ (Fig. 5). This stamping case defined a minimum value of stress, $\sigma_{\min }=-220 \mathrm{MPa}$. The absolute value of the minimum stress (or maximum Von Mises equivalent stress) is less than yield stress $\mathrm{Rp}_{02}$ (Table 1). From a static strength point of view, the material behavior remains elastic and the maximal stress remains inferior to material critical stress.

\subsubsection{Handling load}

A second load case consists in considering the stresses generated by the own weight of the tool (gravity case), in this case the whole tool is subjected to its own weight (2.3 tons). The results lead to a very weak maximal stress, about $0.1 \mathrm{MPa}$ at any points of the tool.

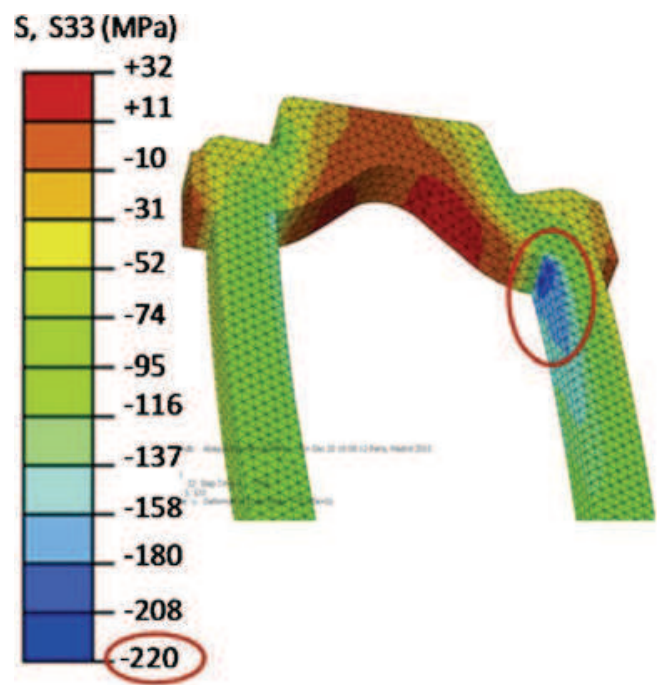

Fig. 5 Result of calculation: $\sigma_{33}$ stress distribution 


\section{Material investigations}

\subsection{Material and mechanical properties}

The chemical composition of EN-GJS-600-3 as determined by EDSX is (in wt\%) $3.3 \mathrm{C}, 0.168 \mathrm{Mn}, 1.14 \mathrm{Si}, 0.02 \mathrm{~S}, 0.06$ $\mathrm{Cr}, 0.06 \mathrm{Ni}, 0.04 \mathrm{P}$, and $0.0157 \mathrm{Mo}$. The microstructure of the investigated material consists of an essentially pearlitic matrix with bull's eyes structure identified by the nodular graphite surrounded by a ferrite zone (Fig. 6).

Monotonic and fatigue tests were carried out on cylindrical specimens with $9 \mathrm{~mm}$ diameter and a gauge length of $25 \mathrm{~mm}$, as illustrated in Fig. 7. Tensile and compressive tests were performed with a strain rate of $10^{-2} \mathrm{~s}^{-1}$ and $10^{-3} \mathrm{~s}^{-1}$, respectively. Strain measurements were completed thanks to an extensometer with a gauge length of $12 \mathrm{~mm}$.

The results from monotonic tests are reported in Table 1.

\subsection{Fatigue experiments}

The choice of the load ratio $\left(R=\sigma_{\min } / \sigma_{\max }\right)$ to be considered in calculation of the lifetime of the tool critical zones via experimental $S-N$ curves is given by the values of minimum and maximum stresses at the same point for all load cases considered. In the example reported here, the minimum stress by the stamping load case is $\sigma_{\min }=-220 \mathrm{MPa}$ in upper radius on internal face of tool. The maximum stress is given by the gravity load case $\sigma_{\max }=0.1 \mathrm{MPa}$. This leads to a load ratio equal to $-2,200$. Our hydraulic machine and the specimen geometry were not suitable for such load ratio. However, for other tool geometry and/or other load cases, the load ratio for critical zones could be different. Consequently, fatigue tests were carried out at room temperature with various load ratios in order to explore the effect of load ratio as noted in the literature [15].

For the components and zones working in compression a load ratio $R=-2$ was chosen. The $R=0.1$ was chosen for the components and zones working in traction as die of stamping tool, finally the load ratio $R=-1$ was studied for

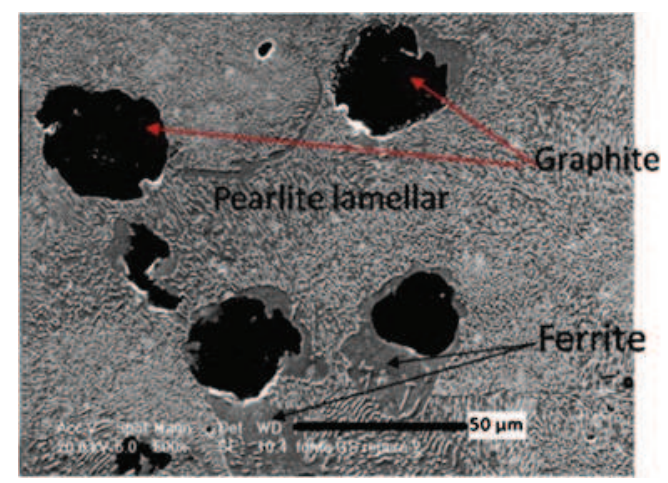

Fig. 6 SEM micrographs of the microstructure of the cast iron ENGGJS-600-3

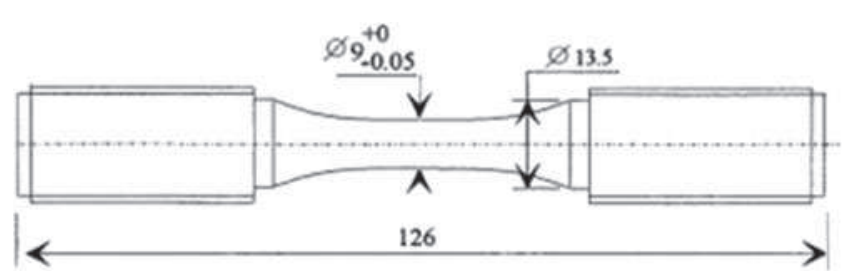

Fig. 7 Specimen geometry

comparing our results with other authors and to represent the zones with a symmetric loading. The studied stresses range varies from 280 to $400 \mathrm{MPa}$ for the load ratio $R=-2$, from 250 to $360 \mathrm{MPa}$ for $R=-1$ and between 140 and $190 \mathrm{MPa}$ for $R=0.1$. Two to eight tests were performed for each stress level.

The frequency in industrial application is about $0.3 \mathrm{~Hz}$ (20 strokes per minute) and the required lifetime is between $10^{5}$ and $10^{7}$ cycles. To reduce the time of material characterization in this fatigue study, a conventional value of $10 \mathrm{~Hz}$ was chosen.

\subsection{Results and discussion}

Figure 8 shows $S-N$ curves for fatigue tests with a load ratio $R=-2$. SEM observations of the initiation site on the fracture surfaces in cast iron specimens, allowed identifying the crack initiation origin. Two groups of specimens were then distinguished: specimens with crack initiation on foundry defects between $100 \mu \mathrm{m}$ and $1 \mathrm{~mm}$ (Figs. 9 and 10) and specimens with crack initiation due to the debonding of nodular graphite in surface (Fig. 11). This last group of specimens is called "without defects" in the following and in Fig. 8 while the first one is called "with defects." The

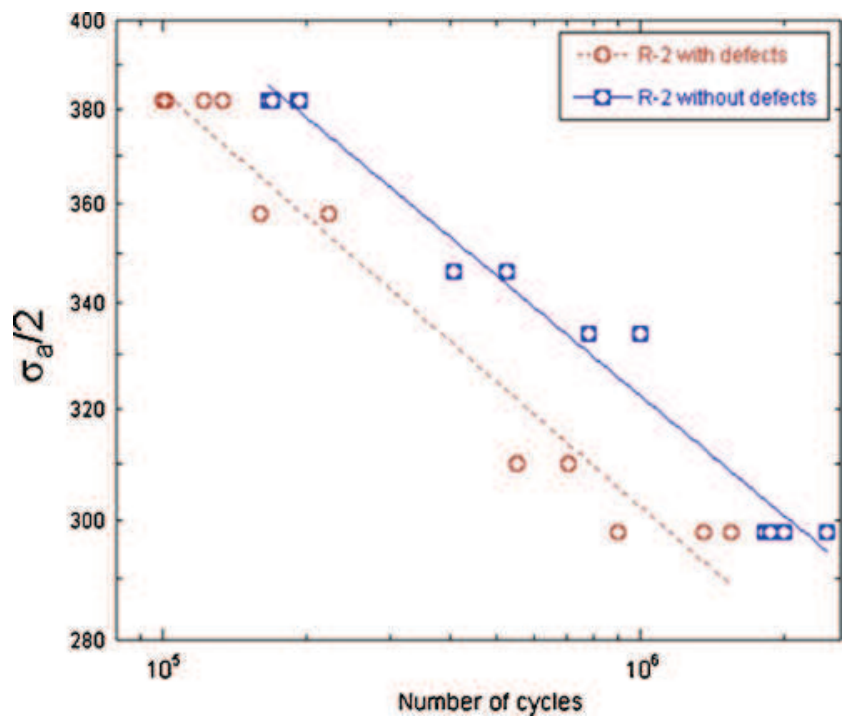

Fig. $8 S-N$ curves of the cast iron EN-GJS-600-3 with and without foundry defects with a load ratio $R=-2$ 


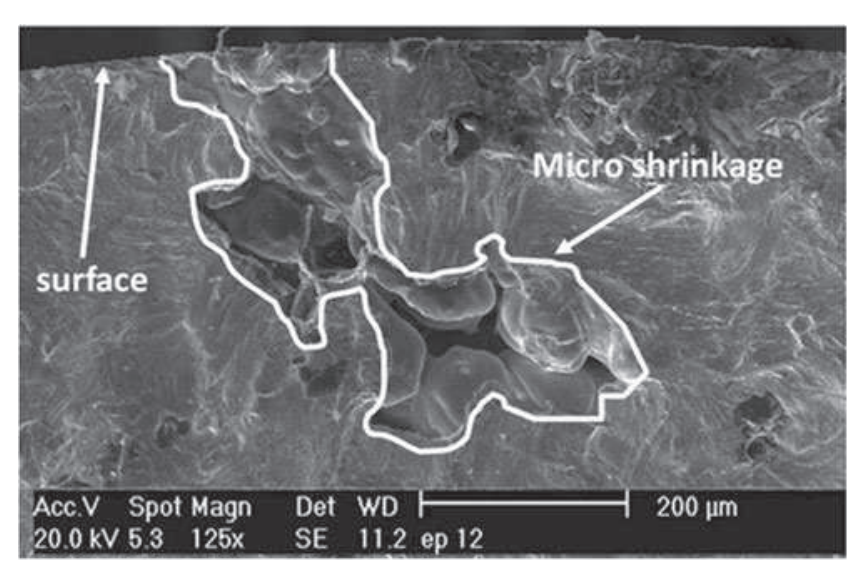

Fig. 9 SEM observations of the initiation site on the fracture surface in cast iron specimens containing a foundry defect: micro-shrinkage in surface

specimens with defects show a reduced fatigue life divided by 2 compared to the specimens without defects. Microshrinkages (Fig. 9) or big grain of graphite (Fig. 10) near the surface were the main causes of crack initiation in the specimen with defects.

The Basquin model is used to represent $S-N$ curves; it is defined by the following equation:

$\sigma_{a} / 2=\sigma_{f}^{\prime} \times(2 N)^{b}$

where $\sigma_{\mathrm{a}}$ is the stress amplitude, $N_{\mathrm{f}}$ the number of failure cycles and $\sigma_{\mathrm{f}}^{\prime}$ and $b$ are respectively the fatigue strength coefficient and fatigue strength exponent. Two distinct sets of parameters are then identified for this load ratio to represent the two groups of specimens (lines in Fig. 8).

For the specimens tested at $R=-1$, SEM observations of fracture surfaces did not bring forward two types of crack initiation sites. All the fracture surfaces exhibited "defects" such as those of specimens with defects tested at $R=-2$.

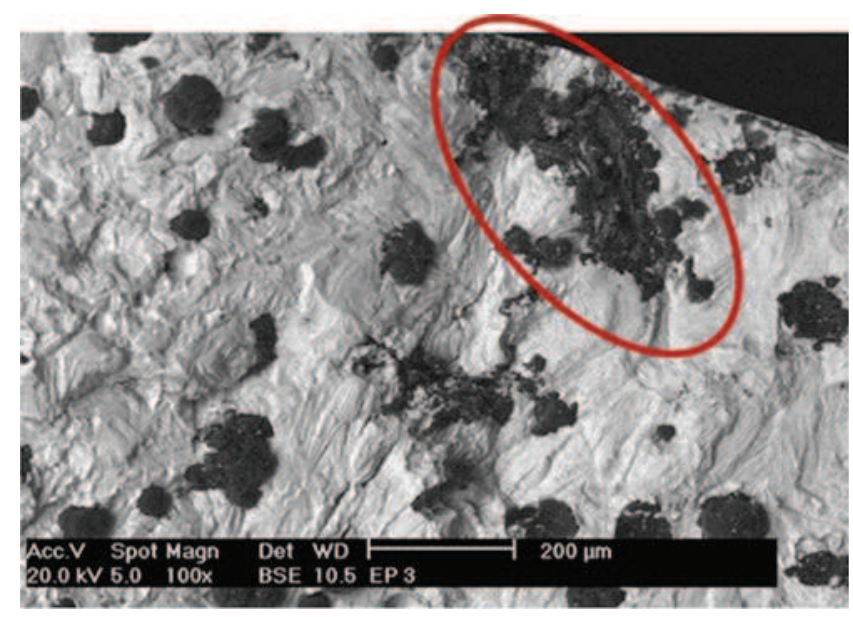

Fig. 10 SEM observations of the initiation site on the fracture surface in cast iron specimens containing a foundry defect: big grain of graphite $(800 \times 150 \mu \mathrm{m})$

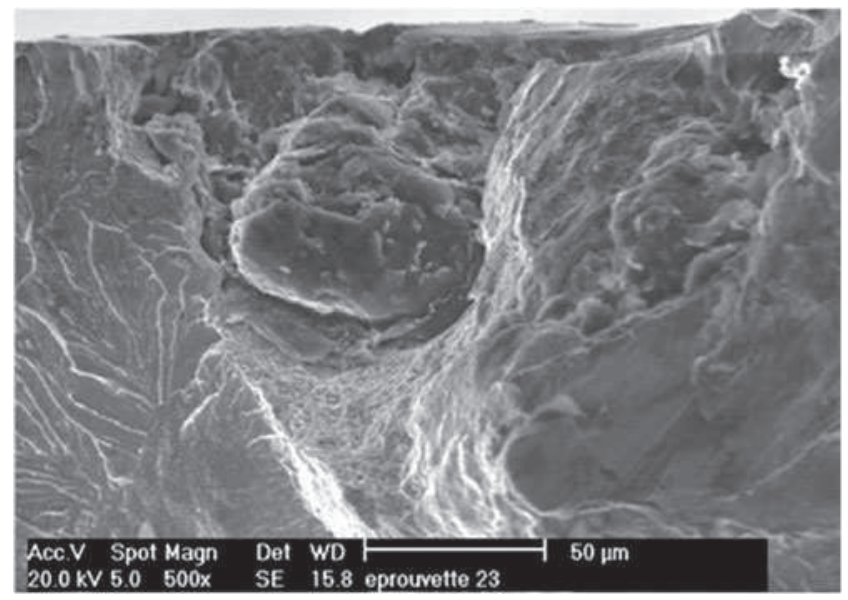

Fig. 11 SEM observations of the initiation site on the fracture surface in cast iron specimens: debonding of nodular graphite in surface

However, the results of fatigue tests at $R=-2$ permitted to create the hypothesis of the reduction of fatigue lifetime by a factor of 2 associated with the presence of foundry defects with a size between $100 \mu \mathrm{m}$ and $1 \mathrm{~mm}$. So, this hypothesis is applied to the case of fatigue test results with a load ratio $R=-1$. Basquin law is then used to model an $S-N$ curve corresponding to specimens without defects for such load ratio. Experimental results for specimens with defects and results provided by this model for specimens without defect are then compared with $S-N$ curves obtained by other authors $[2,7,8]$ on the same material for the same load ratio. It is shown in Fig. 12. A good correlation between the predicted curve without defect of load ratio $R=-1$ and the reported Basquin curves from other experimental studies, is observed. So, this hypothesis can be validated and applied to other load ratios for this material

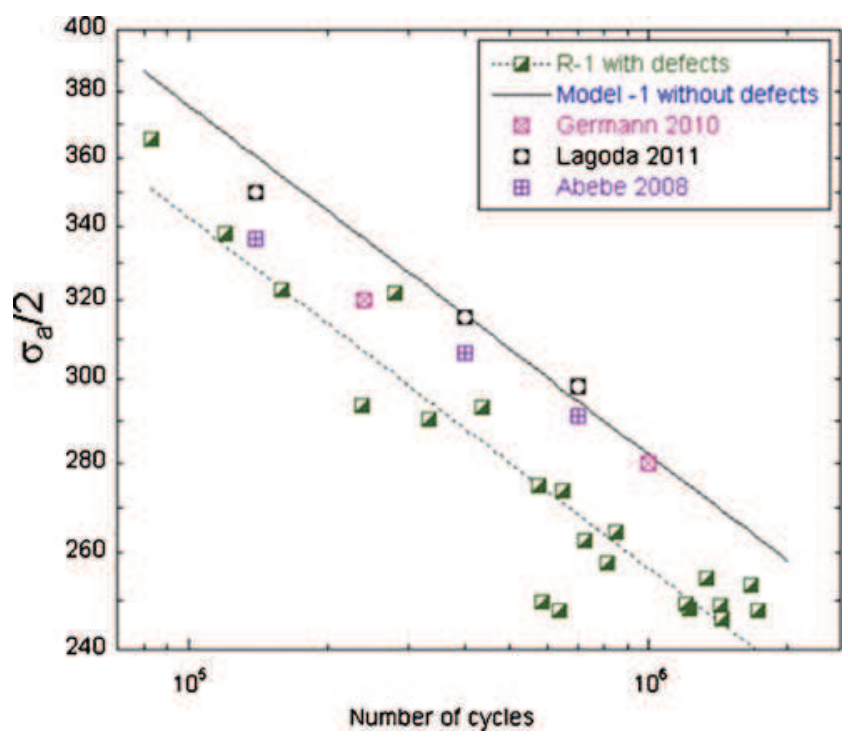

Fig. 12 Comparison of experimental and predicted $S-N$ curves with other authors for the cast iron EN-GJS-600-3 with a load ratio $R=-1$ 


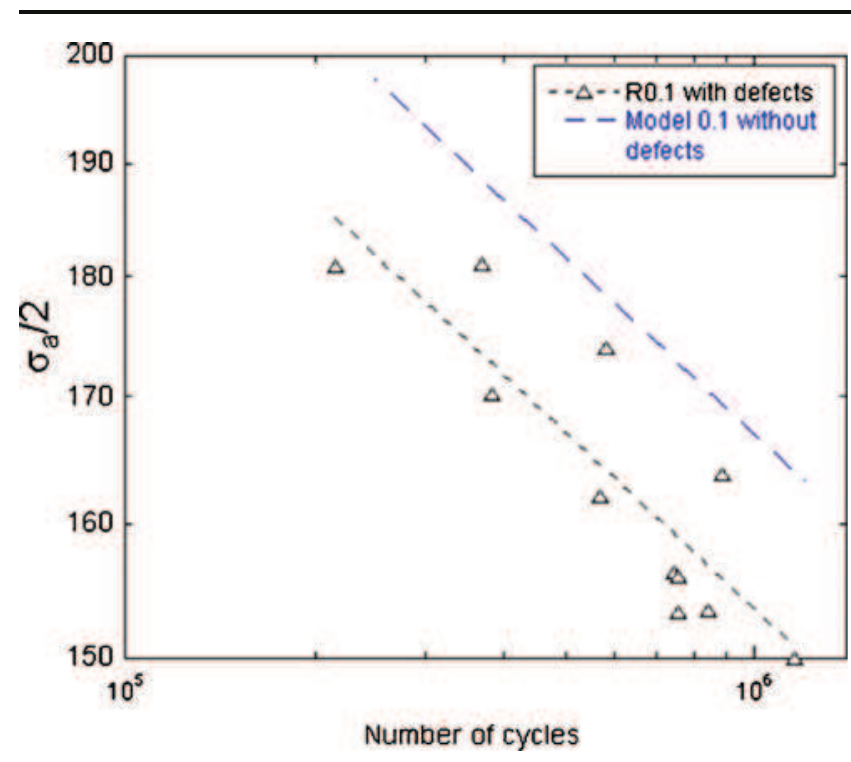

Fig. 13 Experimental and predicted $S-N$ curves for the cast iron ENGJS-600-3 with a load ratio $R=0.1$

Then, the validation of this hypothesis allowed to predict the $S-N$ curve without defects of the load ratio $R=0.1$ from $S-N$ curve of material containing foundry defects (Fig. 13). Table 2 shows the comparison of Basquin parameters of studied load ratios for the cast iron EN-GJS-600-3 with and without foundry defects. Furthermore, these results are compared with other authors at the load ratio $R=-1$. For this case, the Basquin parameters of this study are slightly smaller in comparison with literature results with different slopes for the same load ratio.

The analysis of the fatigue test results with different load ratios (Fig. 14) shows the effect of this parameter is much more important than the presence of foundry defects. The difference of fatigue lifetime between $R=-1$ and $R=-2$ is around a factor of 4 . It can reach a factor of 40 between $R=-1$ and the extrapolation of the $S-N$ curve with a load ratio $R=0.1$. So, it is very important to use the $S-N$ curve with a correct load ratio for calculating fatigue lifetime of components. It is recommended to apply an $S-N$ curve with a negative load ratio in the case of geometrical zone working in compression and a positive load ratio to geometrical zone solicited in tension.

Table 2 Comparison of Basquin parameters from different sources with load ratio $R=-1, R=-2$, and $R=0.1$

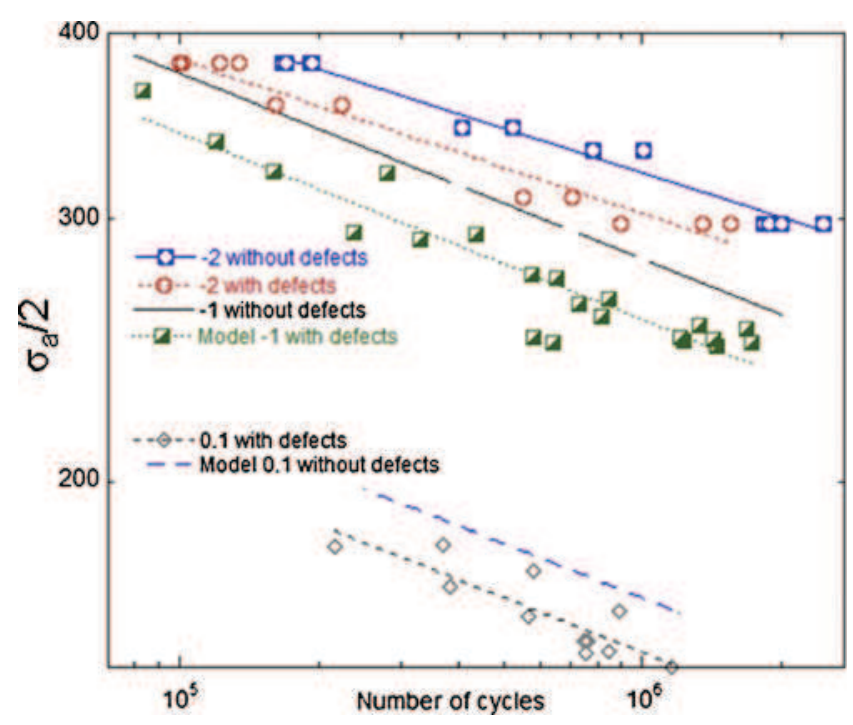

Fig. 14 Comparison of experimental $S-N$ curves with different load ratios for the cast iron EN-GJS-600-3

\section{Fatigue stress analysis}

With the stress results $\sigma_{\min }=-220 \mathrm{MPa}$ and Eq. 1 in the case $R=-2$ with defects, the fatigue lifetime was estimated about $5.10^{8}$ cycles. Faced with this result, a first solution is to validate the tool design (Fig. 1). But if this tool is used for the manufacturing of $10^{6}$ parts, the estimated lifetime is 500 times greater. The tool is over dimensioned. Another solution is to introduce a topological optimization phase in the design methodology in order to improve the structure stiffness and to reduce the weight of the stamping tool. To obtain a lifetime of $10^{6}$ cycles, the minimal stress can then reach $\sigma_{\min }=-400 \mathrm{MPa}$.

\section{Conclusion}

In this paper, a design procedure of stamping tools was proposed. The originality of the proposed approach is to take into account the service loads of the tool (by handling and strikes in press) and the fatigue design. Service charges related to the strike to press were obtained using the results of contact pressure at the interface sheet/tool from a numerical simulation of the stamping operation. These pressures were used as boundary conditions for the structure analysis of tool.

\begin{tabular}{lclllll}
\hline Local ratio & $\begin{array}{l}R=-1 \\
\sigma_{\mathrm{f}}^{\prime}\end{array}$ & $b$ & $\begin{array}{l}R=-2 \\
\sigma_{\mathrm{f}}^{\prime}\end{array}$ & $b$ & $\begin{array}{l}R=0.1 \\
\sigma_{\mathrm{f}}^{\prime}\end{array}$ & $b$ \\
\hline Specimen with defects & 1,453 & -0.12 & 1,258 & -0.1 & 828 & -0.12 \\
Specimen without defects & 1,585 & -0.12 & 1,266 & -0.1 & 901 & -0.12 \\
Lagoda 2001 [2] & 1,131 & -0.1 & & & & \\
Abebe 2008 [8] & 978 & -0.09 & & & \\
Germann 2010 [7] & 1,020 & -0.094 & & & \\
\hline
\end{tabular}


The proposed methodology was applied to a simplified case of a stamp. The contact pressure sheet/tool calculated at the end of strike allowed the evaluation of the stress state in the tool. This was mainly uniaxial compression with a value of $-220 \mathrm{MPa}$. In order to include fatigue analysis in the design procedure, the fatigue of cast iron EN-GJS-600-3 was studied at room temperature. The $\mathrm{SN}$ curves of this material were established with load ratios $R=-2,-1$, and 0.1 . The SEM micrograph allowed to study the crack initiation and to identify two groups of fracture origins. In the case of material without defects, a debonding of nodular graphite in surface causes crack initiation. However, some micro-shrinkages and big grains of graphite near the outer surface are the main cause of crack initiation in the material with defects. Presence of foundry defects with a size between $100 \mu \mathrm{m}$ and $1 \mathrm{~mm}$ in the $9 \mathrm{~mm}$ diameter of specimen is associated with a reduction of fatigue lifetime by a factor of 2 . However, this factor is more accentuated by the load ratio effect that can reach a factor of 40 .

In the application case considered in the present paper, the load ratio encountered by the critical sites of the tool was highly negative. The Basquin curve associated to the lower load ratio explored for the fatigue tests was then used. For specimens with defects, $R=-2$ Basquin curve showed the stress state in the tool leads to a fatigue lifetime around $10^{9}$ cycles. This result validates the current design of the tool. It can also lead to an optimization approach to reduce weight and increase stiffness.

Acknowledgments The authors thank the DGCIS of French Ministry of Industry and the competitive pole iD4CAR for the funding for this work in the EMOA ("Excellence dans la Maitrise des Ouvrants Automobiles") project, PSA Peugeot Citroen for all the facilities and collaboration in the project. The authors acknowledge Thomas Papaix and Serge Tovar for technical support

\section{References}

1. Benslima K, Penazzi L, Mabru C, Ronde-Oustau F, Rezai-Aria F (2011) A new method for advanced virtual design of stamping tools for automotive industry: Application to nodular cast iron EN-
GJS-600-3. In: ESAFORM 2011, AIP Conference Proceedings, pp. $1713-1720$

2. Lagoda T (2001) Energy models for fatigue life estimation under uniaxial random loading. Part II: verification of the model. Int J Fatigue 23(6):481-489

3. Griswold FD, Stephens RI (1987) Comparison of fatigue properties of nodular cast iron production and Y-block casting. Int $\mathrm{J}$ Fatigue 9(1):3-10

4. Hubner P, Pusch G, Krodel L (2004) Fatigue behaviour of cast iron with globular graphite. Adv Eng Mater 6(7):541-544

5. Meggiolaro MA, Castro JTP (2004) Statistical evaluation of strainlife fatigue crack initiation predictions. Int J Fatigue 26(5):463476

6. Nadot Y, Mendez J, Ranganathan N (2004) Influence of casting defects on the fatigue limit of nodular cast iron. Int J Fatigue 26 (3):311-319

7. Germann H, Starke P, Kerscher E, Eifler D (2010) Fatigue behaviour and lifetime calculation of the cast irons EN-GJL-250, ENGJS-600 and EN-GJV-400. Procedia Eng 2(1):1087-1094

8. Abebe BH (2008) Fatigue life assessment of a diesel engine pump part subjected to constant and variable amplitude loading. Master thesis, Bauhaus University

9. Beretta S, Blarasin A, Endo M, Giunti T, Murakami Y (1997) Defect tolerant design of automotive components. Int J Fatigue 19(4):319-333

10. Costa N, Machado N, Silva FS (2010) A new method for prediction of nodular cast iron fatigue limit. Int J Fatigue 32(7):988-995

11. Firat M (2007) Computer aided analysis and design of sheet metal forming processes: part III: stamping die-face design. Mater Des 28(4):1311-1320

12. Ledoux Y, Sebastian P, Samper S (2010) Optimization method for stamping tools under reliability constraints using genetic algorithms and finite element simulations. J Mater Process Technol 210(3):474-486

13. Nilsson A, Birath F (2007) Topology optimization of a stamping die. In: NUMIFORM 2007, Conference Materials Processing and Design: Modeling, Simulation and Applications 908, pp. 449454

14. Gentili A, Penazzi L, Di Pasquale E (1998) Topology optimization in sheet metal forming tool design. In: IDMME'98, pp. 449-456

15. Shirani M, Härkegård G (2011) Fatigue life distribution and size effect in ductile cast iron for wind turbine components. Eng Fail Anal 18(1):12-24

16. Oudjene M, Batoz JL, Penazzi L, Mercier F (2006) A methodology for the $3 \mathrm{D}$ stress analysis and the design of layered sheet metal forming tools joined by screws. J Mater ProcessTechnol 189(13):334-343

17. del Pozo D, Lopez de Lacalle LN, Lopez JM, Hernandez A (2006) Machining of large dies based on the prediction of the press/die deformation. In: Intelligent production machines and systems 2 nd I*PROMS Virtual International Conference, pp. 83-88 